\title{
Fingerprint body myopathy
}

INSERM

\section{Source}

INSERM. (1999). Orphanet: an online rare disease and orphan drug data base. Fingerprint body myopathy. ORPHA:97232

Fing erprint body myopathy is a congenital benign muscle disorder characterised by congenital hypotonia and weakness and by the presence of numerous fingerprint bodies located at the periphery of the muscle fibers. Prevalence is unknown. Less than 20 patients have been described. Few sporadic cases have been observed, as well as cases of recessive transmission. 